\title{
The Influence of Organizational Climate and Job Satisfaction towards the OCB using Employees' Status Variable Control
}

\author{
Suci Fika Widyana \\ Marketing Management Politeknik Pos Indonesia \\ Student of Management Science Doctoral Program Universitas Pendidikan Indonesia \\ Bandung, Indonesia \\ sucifika@poltekpos.ac.id
}

\begin{abstract}
In order to adapt and stay in facing the changes, an organization needs a struggle and multi-task employee. It means that the employees are the one who gives performance more than a prospect in an organization. This kind of behavior doesn't show in one Islamic Foundation in Bandung. It can be seen from the high level of turnover, and the lower overtime frequency showed by the employee. The aims of this study are to find out and analyze the influence of the organizational climate and job satisfaction towards the organizational citizen behavior in an Islamic foundation in Bandung. The methodology of this study used descriptive and survey method. The technique analysis used was a double linear regression while the instrument used was a questionnaire. This study found that the organizational climate conduciveness and job satisfaction has a positive impact towards the organizational citizenship behavior.
\end{abstract}

Keywords- Organizational climate, Job satisfaction, Organizational Citizenship Behavior

\section{INTRODUCTION}

Organizational Citizenship Behavior (OCB) is treated as intangible. This behavior doesn't get much appreciation since the behavior such as 'helping', and hospitalities are difficult to measure. However, a study shows that the effectiveness of organization will rise when the employees are willing to do the over the task from the company itself or their college.

Robin states in his book that organizational citizenship behavior is main dependent in study of behavior organization. It is important to hold a research in this area since the organization will always face the changes. The changes can be in terms of downsizing, change of task and duty, organization's hope for having a creative employee in finding new method to fix the job's efficiency, and attention to turnover. When the employees are decreasing, the organization depends on the staying employees and expects them to do more tasks than they can do. That's a strong OCB is expected to be owned by the employee.

According to the interview result done by the writer, with the head of the human resources on February 18 2014, the Islamic Foundation in Bandung shows a weak organizational citizenship behavior. It can be seen from the low of overtime frequency in which the employees only want to do the extra duty for the sake of paid overtime duty. This behavior is represented the Conscientiousness dimension in OCB, which believes that volunteering action is not an employee's duty.

The low of OCB can also be seen from the high turnover level which is $26 \%$ in 2013 . This situation shows that there was no tolerant for worst situation. It means that this situation is the representative of sportsmanship in Organizational Citizenship Behavior. Employees who have low levels of OCB have a tendency to leave the organization higher than the employees who have high OCB [1].

In this study, aspects that can be affected on OCB are the organizational climate and job satisfaction. The conducive organizational climate will affect to job satisfaction, so that, the employee will perform the behavior and do things even though they are not their job description.

According to Schneider et al.[2] Organizational climate focuses on the perception of organization's policy, practices, procedure between the formal and informal groups in an organization.

In additional, the other factors affect the OCB is job's satisfaction. Extrinsic and intrinsic job satisfaction is very important in predicting citizenship behavior [3]. The satisfaction depends on the description of fair treatment and procedures. When the employees believe that they are given a fair treatment, they will also want to do something overtime.

If the climate is quite conducive and the job satisfaction is formed, thus, the employee will be more productive in doing the duty, and it will lead them to do the extra role behavior without asking for any payment.

\section{ORGANIZATIONAL CLIMATE, JOB SATISFACTION AND ORGANIZATIONAL CITIZENSHIP BEHAVIOR}

DW Organ and Bateman defines "organizational citizenship behavior as individual behavior that is discretionary, not directly or explicitly recognized by the formal reward system, and that in the aggregate promotes the effective functioning of the organization" [4]. According to Organ there are some factors affected the member behavior such as: culture and organizational climate, personality and mood, perception about organization's supports and 
commitment; perception about quality of interaction between the senior and junior, years of service, gender, and job satisfaction. In other words, membership behavior is beneficial behavior, which can't be asked with formal role or contract or re-compensation such as helping your college's duty, don't want to take a rest, did duty without someone asks, and solving the problem. Organ divides the citizen behavior into seven dimensions; they are: Altruism, Conscientiousness, Sportsmanship, Courtesy, Civic Virtue, Peacekeeper, and Cheerleader.

From the several opinions, membership behavior is a behavior showed by the flexible employees to do extra and overtime task without looking for extra payment, complement and awards from the other's colleges which contributed to the efficiency, effectiveness, and productivity.

The result of study about the influence on OCB towards organization performance. Podsakoff et al, [5] said that the benefits of OCB are as follows: a) OCB raises the productivity of workmate; b) OCB raised the manager productivity; c) OCB helps the organization to have a resource from all managements and organizational; d) OCB helps the organization to suppress the rare resource to keep the function of the group; e) OCB is an effective place to coordinate the group activity; f) OCB raises the ability of organization to attract and keep the best employees; g) OCB raises the stability of organizational performance; h) OCB helps the ability of adaptation in the change of environment.

Organizational climate according to Tagiuri and Litwin in Wirawan [6] is "...a relatively enduring quality of the internal environment of an organization that (a) is experienced by its numbers, (b) influence their behavior, and can be described in terms of the values of a particular set of characteristic (or attributes) of the organization." It is in line with positive perceptions of organizational climate influence on increasing OCB and performance of the organization, and OCB in turn has a positive and significant impact on organizational performance.

In conclusion, work climate is an individual perception about internal environment such as characters. It can affect the employees' behavior and create the characteristics of the organization. Organizational climate is caught individually through perception. That is why it is defined as a measure cognitive product towards someone's work environment. Each employee will have different reaction in dealing with work environment and organizational climate.

Organizational climate shows a life's steps of the organization which is felt and perceived by members. Each member from managerial until the worker, they want to have a good climate since it will provide more benefit such as good achievement and job's satisfaction.

In this study, organizational climate which will be measured is Robert Stringer's idea in A. Hardjna [7]. Robert Stringer's believes that characteristic or climate dimension affects the motivation of the member, thus, there are six dimensions, they are Structure, Standards, Responsibility, Recognition, Support, and Commitment.
According to Gibson [8] Job's satisfaction is a person's attitude towards their work. That attitude comes from their perception of his work. There are five dimensions in job satisfaction, they are Work It Self; Pay; Promotion; Supervision; Co-workers.

According to Robbins [9] the causes from job's satisfaction are Satisfaction and Performance (job satisfaction and performance have a positive relation/connection, the higher job satisfaction the employees get. The higher performance is shown by the employee); Satisfaction and Organizational Citizenship Behavior (The satisfied employee tends to react positive to the organization and has a normal expectation); Satisfaction and Customer (the satisfied employee tends to be more friendly and responsive to the customers); Satisfaction and Turnover (job satisfaction has negative relation with the turnover. Factors behind it are age, commitment and economics condition); Satisfaction and Absenteeism (If the job satisfaction is high, the absence will be in low level); Satisfaction and deviation (Unsatisfied feeling will lead to several causes such as creating worker alliance, stealing, and moving too slow).

David A. Foote and Thomas Li-Ping Tang [10] had found the relationship between job satisfaction, and OCB was shown to be significant, as was the relationship between team commitment and OCB.

According to theories above, this study provides hypotheses that conduciveness in organizational climate and level of job satisfaction has a positive affection towards the OCB.

\section{RESEARCH METHODOLOGY}

The object in this study is the organizational climate and job satisfaction as independent variable and OCB as the dependent variable. This research investigates the employees' perception of the organizational climate and job satisfaction towards OCB by using employees' status as the variable control.

This study is descriptive and verificative research by using survey method. Through this way, this study describes the variable of organizational climate, job satisfaction and OCB. The verificative method is aimed to test the truth through gathering data.

The samples in this study were gathered by using Restricted Sample Multiple Stage Sample method by using Slovin formula. The samples were 167 employees about of 287 employees. The data was analyzed by double linear regression, meanwhile questionnaires were used as the instrument.

\section{FINDING \& DISCUSSIONS}

For describing the perception of the employee towards organizational climate, job satisfaction and OCB, this study used cross tab analysis, the result as follows:

\section{A. Organizational Climate Variable}

Table I shows that the result of recapitulation of respondent's reaction towards the dimensions in organizational climate. 
TABLE I. THE RESULT OF RECAPITULATION OF RESPONDENT'S REACTION TOWARDS THE DIMENSIONS IN ORGANIZATIONAL CLIMATE

\begin{tabular}{|c|c|c|c|}
\hline No. & $\begin{array}{c}\text { Organizational } \\
\text { Climate's dimension }\end{array}$ & Score (F) & Percentage (\%) \\
\hline 1 & Structure & 2098 & 18.16 \\
\hline 2 & Responsible & 2326 & 20.14 \\
\hline 3 & Standard & 1673 & 14.48 \\
\hline 4 & Recognition & 1851 & 16.02 \\
\hline 5 & Support & 1824 & 15.79 \\
\hline 6 & Commitment & 1779 & 15.40 \\
\hline & Total & 11551 & 100 \\
\hline
\end{tabular}

a. Resource: Result of analysis in June 2014

Table I shows that the responsible has the highest score which is $2326(20,14 \%)$. Meanwhile the standard has the lowest score which is $1673(14,48 \%)$. Thus from the six dimensions, responsible is the most affective and give the biggest contribution to the Islamic Foundation. Meanwhile the standard gives the least contribution to the Foundation.

This situation is understood since the Foundation respects to all of spiritual activity and goo characters such as responsibility. All members of the foundation do the good (honesty, steadfast, and sincere) and strong (courage, discipline and dependable) characters. The standard dimension can be seen in the Foundation since the standard, and target is not equal with the employee's abilities.

The condition of organizational climate describes that there is no difference between the contract or permanent employees. Due to the cross tab analysis, there are 160 employees who believe that the organizational climate is conducive. It consists of 81 employees $(50,6 \%)$. Are the contract employee and 79 employees $(49,4 \%)$ are permanent employees. Further, it means that there is a similarity opinion towards the organizational climate. So that, even though the status controls the organizational climate, the result won't' have any different.

\section{B. Job Satisfaction Variable}

Table II shows the result of recapitulation about job satisfaction in Islamic Foundation in Bandung.

TABLE II. The RESUlt OF RECAPITUlation IN Job SATISFACTION

\begin{tabular}{|c|c|c|c|}
\hline No. & $\begin{array}{c}\text { Job Satisfaction } \\
\text { Dimension }\end{array}$ & Score (F) & Percentage (\%) \\
\hline 1 & Work it self & 1783 & 20.34 \\
\hline 2 & Pay & 1799 & 20.52 \\
\hline 3 & Promotion & 1171 & 13.36 \\
\hline 4 & Supervision & 1979 & 22.58 \\
\hline 5 & Co-Workers & 2033 & 23.19 \\
\hline & Total & 8765 & 100 \\
\hline
\end{tabular}

${ }^{\text {b. }}$ Resource: Result of analysis in June 2014

The table II shows that co-workers are the highest score which is $2033(23,19 \%)$. It is understandable since the Foundation puts family above everything. Co-workers are treated as a reminder that can tell the members' weaknesses and strength. Co-workers can be the member's discussion partner.

However, promotion has the lowest which is 1171 $(13.36 \%)$. It is understandable since there is no carrier path in the Foundation. The position doesn't mean something. It is just the job description.
So that, from the six dimensions, the co-worker gives biggest contribution to the Foundation. Meanwhile, the promotion gives the least contribution.

The result of cross tab analysis in terms the job satisfaction, there are 147 employees stated that they had satisfied job satisfaction. They consisted of 79 contract employees $(53,7 \%)$ and 68 permanent employees (46, 3\%). Meanwhile, there were 20 employees had very satisfied job's satisfaction. They consisted of 6 contract employee (30\%) and 14 permanent employees (70\%).

The data show that job satisfaction can be defined by the presence of employee status. It shows that both contract and permanent employee are having the same job satisfaction. However, in terms of very satisfied level, the permanent employee dominates the level.

\section{Organizational Citizenship Behavior (OCB)}

Table III shows the result of recapitulation of respondents towards the organizational citizenship behavior.

The table III shows that the courtesy is the highest score with 2089 (16, 88\%). Meanwhile, the peacekeeper is the lowest score with $1357(10,7 \%)$. So that, from the sevens dimension, courtesy gives the most contribution in the Foundation. It is understandable since the foundation is having a good relationship with the employee. The foundation treats the employees like its own family.

TABLE III. RECAPITULATION OF RESPONDENTS TOWARDS THE ORGANIZATIONAL CITIZENSHIP BEHAVIOR

\begin{tabular}{|c|c|c|c|}
\hline No. & $\begin{array}{c}\text { Job Satisfaction } \\
\text { dimension }\end{array}$ & Score $(\mathbf{F})$ & Percentage (\%) \\
\hline 1 & Altruism & 1948 & 15.74 \\
\hline 2 & Conscientiousness & 1820 & 14.71 \\
\hline 3 & Sportmanship & 1790 & 14.47 \\
\hline 4 & Courtesy & 2089 & 16.88 \\
\hline 5 & Civic Virtue & 2005 & 16.20 \\
\hline 6 & Peacekeeper & 1357 & 10.97 \\
\hline 7 & Cheerleader & 1364 & 11.02 \\
\hline & Total & 12373 & 100 \\
\hline
\end{tabular}

c. Resource: Result of analysis in June 2014

Meanwhile, peacekeeper dimensions give the least contribution to the foundation. It is understandable since the Foundation provides a counselor to handle all the problems faced by the employee and the foundation itself.

According to employee status, there are 127 employees. Have strong organizational citizenship behavior. It consists of 60 contract employee $(47,2 \%)$ and 67 permanent employees $(52,8 \%)$. There are 40 employees who have very strong organizational citizenship behavior. It consists of 25 contract employee $(62,5 \%)$ and 57 permanent employees $(37,5 \%)$

The data show that job satisfaction can be defined by the presence of employee status. It shows that both contract and permanent employee are having the same job satisfaction. However, in terms of very satisfied level, the permanent employee dominates the level. 


\section{The Influence of Organizational Climate and Job Satisfaction towards the Organizational Citizenship Behavior using Employees' Status Variable Control}

To measure how big the influence of organizational climate and job satisfaction towards OCB is, double linear regression is used by SPSS 20.0 application. The results are below:

TABLE IV. Result of T TEST ORganizational Climate $\left(\mathrm{X}_{1}\right)$ AND Job SATISFACTION $\left(\mathrm{X}_{2}\right)$ TOWARDS ORGANIZATIONAL CITIZENSHIP BEHAVIOR (Y)

\begin{tabular}{|l|l|l|l|l|c|}
\hline \multicolumn{1}{|c|}{ Model } & \multicolumn{2}{|c|}{$\begin{array}{c}\text { Unstandardized } \\
\text { Coefficients }\end{array}$} & $\begin{array}{c}\text { Standardize } \\
\text { Coefficients }\end{array}$ & \multirow{2}{*}{ t } & \multirow{2}{*}{} \\
\cline { 2 - 6 } & \multicolumn{1}{|c|}{ B } & $\begin{array}{c}\text { Std. } \\
\text { Error }\end{array}$ & Beta & & \\
\hline 1 (Constant) & 33.801 & 6.866 & & 4.923 & .000 \\
Iklim Organisasi & .469 & .094 & .361 & 4.987 & .000 \\
Kepuasan Kerja & .236 & .084 & .203 & 2.804 & .005 \\
\hline
\end{tabular}

d. Resource: Result of anysis in June 2014

The result shows that value of $\mathrm{t}=4,987$ and significant value is 0,000 , meanwhile $t$ table score is 1,65 and $\alpha=0,05$. It means that $\mathrm{t}>$ table and sig value $<0,05$, so that, $\mathrm{H} 0$ is rejected and $\mathrm{Ha}$ is accepted. In conclusion, there is a positive and significant conductivity organizational climate in level organizational citizenship behavior which is $(\beta) 2=0,130321$ or $13,03 \%$. Meanwhile in terms of job satisfaction the $\mathrm{t}$ score $=$ 2,804 and significant value is 0,006 ; the $t$ table $=1,65$ and $\alpha 0$, 05 . It means that $\mathrm{t}>$ table and sig value $<0,05$, so that, $\mathrm{H} 0$ is rejected and $\mathrm{Ha}$ is accepted. In conclusion, there is a positive influence and significant from job satisfaction to organizational citizenship behavior. The influence of job satisfaction to organizational citizenship behavior is $(\beta) 2=0,041209$ or 4 , $12 \%$.

It can be concluded that there is a positive and significant conductivity organizational climate in level organizational citizenship behavior. It is in line with Dennis W. Organ [11] who says that the organizational climate and culture can be the strong cause in developing employee's behavior. In the positive organization, the employee wants to do the over duty and support the aim of organization when they realize their role in an organization. The employees wanted to be appreciated fairly by the organization.

In terms of job satisfaction, it is concluded that there is a positive influence and significant from job satisfaction to organizational citizenship behavior. It is in line with the hypothesis proposed by Organ \& Ryan [12] who defines that when the employees feel satisfy with their duty, they will appreciate the company and perform positive behavior.

Another research done by Kelly L. Zellars and Bennett J. Tepper [13] shows that job satisfaction affects the organizational citizenship behavior. The employee who felt satisfy with the tasks, they will show higher organizational citizenship behavior then the employees who don't feel satisfy.

\section{CONCLUSION \& SUGGESTIONS}

According to analysis and discussion, there are some conclusions that can be conducted, such as:
Conductivity of organizational climate in Islamic Foundation in Bandung is described as: Both contract and permanent employees perceive the situation as conducive. Meanwhile the job satisfaction, some of the permanent employees tend to have very satisfied job satisfaction, but the contract employees tend to have satisfied job satisfaction. In terms of organizational citizenship behavior, the contract employees show a very strong organizational citizenship behavior meanwhile the permanent employees show strong organizational citizenship behavior. Thus, the status of the employee does not influence the organizational climate but job satisfaction and organizational citizenship behavior.

The Conductivity of organizational climate and job satisfaction gives a positive influence to organizational citizenship behavior in Islamic Foundation in Bandung. Thus, the more conducive organizational climate in organizations, the stronger organizational citizenship behavior will they have. It is also the same with job satisfaction, when the job satisfaction raises the organizational citizenship behavior will get stronger.

Due to the data analysis, there are some suggestions provided for this study, such as:

Since the OCB is influenced by organizational climate, thus, to improve the organizational citizenship, the organization needs to keep or improve the organizational climate. This idea follows by the situation when it deals with supporting from top managerial, giving achievement, and fair punishment for employees who doesn't obey to the rule. It suggests will cause the comfortable environment and raise the commitment and loyalty.

The second suggestion is that the Foundation focuses more on the promotion and career path for the employee. It is because the promotion will help the employee to have spirit and build creativity. The raising of job satisfaction can be done by raising the competency of the employee, so that, they can have an ability to do their duty, get chance to participate and take a decision in their institution.

\section{REFERENCES}

[1] X.-P. Chen, C. Hui, and D. J. Sego, "The role of organizational citizenship behavior in turnover: Conceptualization and preliminary tests of key hypotheses.," J. Appl. Psychol., vol. 83, no. 6, pp. 922-931, 1998.

[2] B. Schneider, M. G. Ehrhart, and W. H. Macey, "Organizational climate and culture.," Annu. Rev. Psychol., vol. 1, no. 12, pp. 361-388, 2013.

[3] J. Mohammad, F. Q. Habib, and M. A. Alias, "Job Satisfaction and Organisational Citizenship Behaviour: an Empirical Study At Higher Learning Institutions," Management, vol. 16, no. 2, pp. 149-165, 2011.

[4] J. B. Becton, W. F. Giles, and M. Schraeder, "Evaluating and rewarding OCBs," Empl. Relations, vol. 30, no. 5, pp. 494-514, 2008.

[5] P. M. Podsakoff, S. B. MacKenzie, J. B. Paine, and D. G. Bachrach, "Organizational Citizenship Behaviors: A Critical Review of the Theoretical and Empirical Literature and Suggestions for Future Research," J. Manage., vol. 26, no. 3, pp. 513-563, 2000.

[6] Wirawan, Budaya dan Iklim Organisasi, Teori dan Aplikasi dan Penelitian. Jakarta: Salemba Empat, 2007.

[7] A. Hardjana, "Iklim Organisasi : Lingkungan Kerja Manusiawi," Ilmu Komun., vol. 3, no. 1, pp. 1-36, 2006.

[8] J. James L. Gibson; John M. Ivancevich ; James H. Donelly, Organisasi (Perilaku, Struktur, Proses), Kelima. Jakarta: Erlangga, 1985.

[9] S. P. Robbins and T. A. Judge, Perilaku Organisasi, 12th ed. Jakarta: 
Salemba Empat, 2012.

[10] D. a. Foote and T. Li Ping Tang, "Job satisfaction and organizational citizenship behavior (OCB)," Manag. Decis., vol. 46, no. 6, pp. 933947, 2008.

[11] S. B. M. Dennis W. Organ, Philip M. Podsakof, Organizational Citizenship Behavior: Its Natur Antecendents and Consequences. California 91320: SAGE Publication,Inc., 2006.

[12] D. W. Organ and K. Ryan, "A Meta-Analitic review of Attitudinal and dispositional predictos of Organizational Citizenship Behavior," Personnel Psychology, vol. 48, no. 4. pp. 775-802, 1995.

[13] K. L. Zellars and B. J. Tepper, "Beyond Social Exchange: New Directions For Organizational Citizenship Behavior Theory And Research," Res. Pers. Hum. Resour. Manag., pp. 395-424, 2015. 